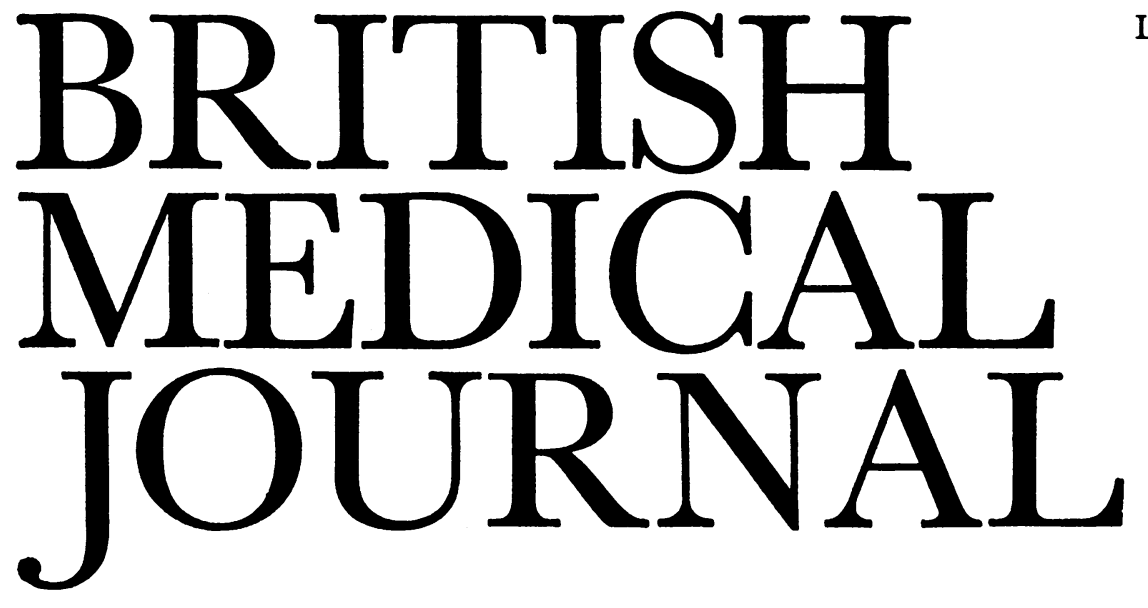

LONDON, SATURDAY 3 JANUARY 1976

\title{
What about the real problems?
}

The prominence given to the current conflicts between the DHSS and the doctors has had the unfortunate effect of obscuring the real, long-term difficulties of the NHS. Urgency has, as usual in politics, been given more attention than importance. There are intractable problems, however, which must be tackled, and late last year an informal group of doctors, journalists, and academics met at Canterbury to examine the manpower crisis within the NHS: what they had to say is reported in this ( $\mathrm{p} 25)$ and the next two issues.

For most of its existence the NHS has had to struggle with two unbalanced equations. Firstly, each year our medical schools in Britain produce rather more graduates than we need to replace consultants and general practitioners who die or retire but far too few to provide enough hospital junior staff for our hospitals. In rough figures we need about 2500 graduates to replace doctors retiring from career posts and about 4500 graduates to staff our hospitals: in fact just over 3000 new doctors will graduate this year. Secondly, there are far too many would-be entrants to the popular specialties such as general surgery and too few to the shortage specialties such as geriatrics, psychiatry, mental subnormality, and anaesthetics. These imbalances have been solved by large numbers of medical immigrants from the Indian subcontinent and Africa.

But times are changing. The TRAB examinations, which test foreign graduates' medical competence and their familiarity with English, have had failure rates of $60-70 \%$, and must reduce the numbers of doctors coming to Britain, as well as discouraging some from ever trying. Our economic decline is making Britain less attractive to foreign doctors, and they themselves are rebelling against their use as "pairs of hands" doing jobs that British graduates refuse. New ways will have to be found to balance these equations, and fairly quickly.

One solution, argued by Professor CT Dollery (27 December, p 750), is a crash expansion programme in our medical schools. If we trained more doctors we could staff our hospitals without reliance on overseas graduates, and a rapid and major change in the proportions of consultant and junior posts (with inevitable changes in the consultant's job-specification) could solve the imbalance between the numbers of training and career posts. But is it likely that Government money could or would be found for such a programme-especially at a time when so many young doctors are dissatisfied with their prospects here and are looking overseas?
A second, equally radical alternative was discussed at the conference. Perhaps we have too many doctors in the NHS doing the wrong sort of work. Other countries-developed and developing - are being forced by economic circumstances to make greater use of ancillaries in the provision of medical care: should Britain not be doing the same?

Medical ancillaries should not be seen as doctor-substitutes, offering a second-rate service to discontented patients. In general practice, for example, nurses are often better than doctors at managing common and recurrent childhood illnesses, at follow-up visits to elderly patients, and at giving advice and instruction on contraceptive methods and infant feeding. Their inclusion in the practice team can free doctors for their proper work of diagnosis and advice, so improving the quality of care provided and the satisfaction found by doctors-and the nurses-in their work. Whether their use can lead to real financial savings remains to be seen-for, as J A Butler observed at the conference, we still have no objective measure of the community's needs for primary care.

Within the hospital service there is no doubt of the value of specialist nurses in intensive and coronary care units, renal dialysis units, and other specialist fields. In North America technicians are being used as surgical assistants; schoolleavers can quickly learn a single microsurgical technique and carry it out repeatedly and accurately. How many of the routine tasks carried out by resident medical staff really require a doctor-except for medicolegal purposes or because patients expect it?

While more use is being made of ancillaries and technicians so far there has been little effort to cut back on extravagant use of doctors. Part of the explanation must be the lack of any incentive for planners to look for radical solutions to manpower problems. Other technically advanced countries have found many different solutions to the staffing of their medical services, with some relying heavily on ancillaries and nurses, and others (such as the USSR) having high numbers of relatively poorly paid doctors. The total numbers of staff per head of population is remarkably uniform. If, then, we are to solve our manpower equations we need to look at these alternatives - and at the best use of women in medicine and the role of overseas graduates-two other topics discussed at the Canterbury conference. The first priority, however, is surely a manpower planning unit for the whole NHS, not just the hospital service. We have no money: we must think. 